\title{
Effect of seasonal radiation and daylength shifts on growth and development of spray carnation. 2. Flower initiation
}

\author{
D. Klapwijk
}

Glasshouse Crops Research Station, P.O. Box 8, 2670 AA Naaldwijk, Netherlands

Received 20 January 1986; accepted 24 February 1987

Key words: spray carnation, season, flower initiation, flowering.

\begin{abstract}
Growth and development of 32 year-round plantings of spray carnation (Dianthus caryophyllus L.) cv. West Pink were determined. Pinching between March and July resulted in a growth period between pinching and microscopically visible flower initiation of approximately 70 days. When pinching took place between August and October this period increased linearly to 180 days. When pinching took place in November or later the growth period till flower initiation decreased with one day for every day pinching was delayed. This resulted in a microscopically visible flower initiation on 7 May in many plantings. At cellular level flower initiation will take place in mid April, i.e. at a daylength of approximately 13 hours. Immediately after flower initiation the shoot exhibits an abrupt increase in extension rate. Frequent measurement of shoot length thus offers a non-destructive method to determine flower initiation.

In this experiment standard carnations (cv. White Sim) were compared with spray carnations. No substantial differences were found. It was concluded that there were no principal differences between spray carnations cv. West Pink and 'Sim' cultivars of standard carnation with respect to daylength effects.

Results with spray carnation agree fairly well with published year-round data on the total growth period between planting or pinching and flowering of standard carnation.
\end{abstract}

\section{Introduction}

In a previous paper (Klapwijk, 1987), a description was given of seasonal radiation effects on vegetative growth of spray carnation. The aim of the present research was to study the effect of natural variation in daylength on flower initiation in carnation. With improved knowledge of the effect of natural daylength on flower initiation it will probably be possible to make better use of artificial daylength extension. This may shift production peaks to periods with lower production and higher prices. 


\section{KLAPWIJK}

Much work has been done on the influence of artificial changes in daylength on flower initiation, but no data are available on the year-round effect of natural variation in daylength. Several workers (Abou Dahab, 1967; Anon., 1982; Bing, 1960; Bunt, 1973; Holley, 1959; Nelson \& Kiplinger, 1957; Münch, 1973) have collected year-round data concerning the total period between pinching or planting and full bloom. None of them, however, paid attention to the question when during the period from pinching until flowering the change into the reproductive stage took place. A comparison of our results with the work of other authors can therefore only be made on the total growing periods till flowering, since our experiments were conducted specifically to achieve a year-round series of data with respect to the moment of flower initiation.

Most work on year-round development of carnation has been carried out with 'Sim' cultivars of standard carnatior. An additional question was whether the data on standard carnations would also be valid for spray carnations.

\section{Materials and methods}

The procedures of year-round cultivation of carnation plants for this work were the same as described earlier by Klapwijk (1987). All 32 plantings were sampled regularly and in each sample the development of the growing meristem was examined to determine at what date the shoot became generative. The developmental stages were chosen according to Hanzel et al. (1955) and Cheng \& Langhans (1971). The growth period until flower initiation began at the date on which the well-established plants were pinched. The day numbers used in the figures are based on 1 January = 1.

\section{Results and discussion}

\section{Critical daylength}

The growth period between pinching and flower initiation was approximately 70

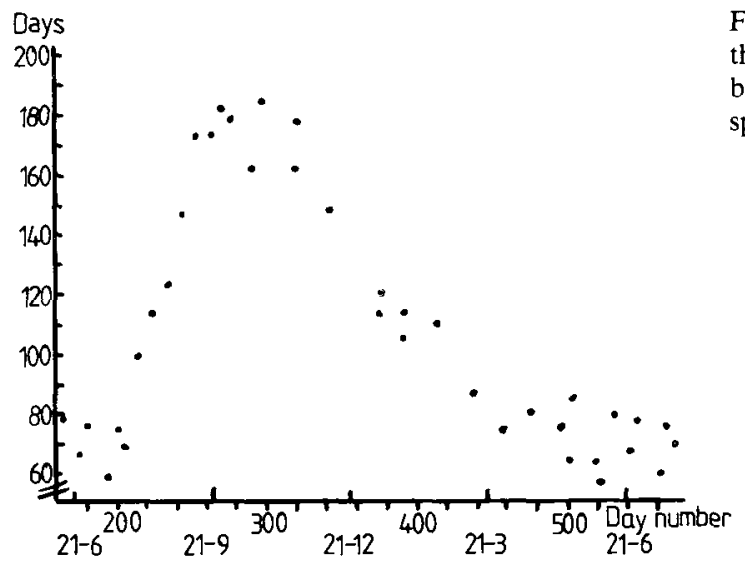

Fig. 1. The influence of the pinching date on the growth period (days of carnation shoots between pinching and flower initiation of spray carnation. 


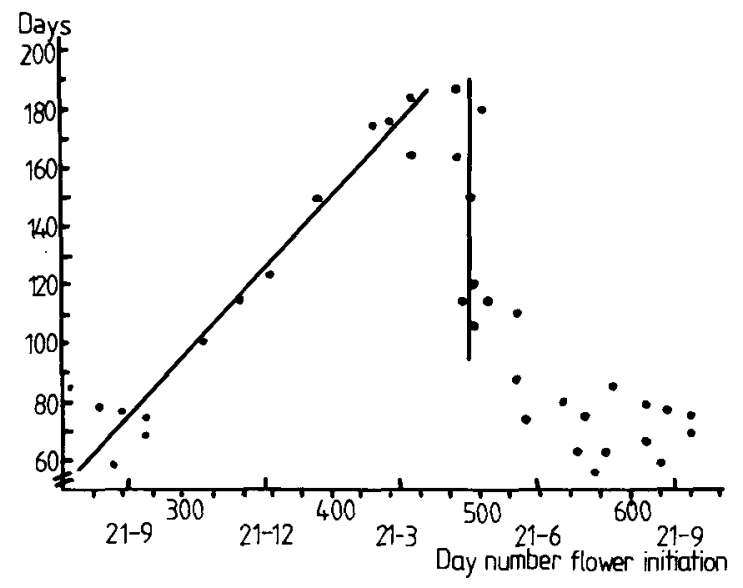

Fig. 2. Growth period (days) of carnation shoots between pinching and flower initiation, in relation to the date of flower initiation. Regression equation: $244 \leqslant$ $x \leqslant 454 ; y=0.541 x-68.4 ; r=0.984$.

days when pinching occurred between March and August (Fig. 1). Obviously, the daylength for flower initiation was sufficient. To demonstrate when initiation took place, the data of Fig. 1 were transformed to Fig. 2, in which the growth period from pinching to flower initiation is related to the date when initiation was microscopically visible. The difference between these figures is striking. There were eight batches of plants in this series which exhibited flower initiation at approximately the same moment, while the pinching date for those batches varied between 26 October and 27 January, i.e. 90 days apart. In other words, regardless of the date of pinching, they all started flower initiation at about the same time in the season; the average date was 7 May (= day number 492). Probably this picture reflects the exceeding of a critical daylength required for flower initiation. When flower initiation was visible under the microscope on 7 May, the switch from vegetative to generative growth at cellular level must have taken place at least some weeks earlier. This implies a critical daylength for flower initiation of approximately 13 hours. This critical daylength is not in agreement with the lighting procedures used in commercial carnation production. Growers apply daylength extension to 24 hours mainly in January and February, which decreases the time to flowering by a few weeks. Based on the present results (Fig. 1), February-March seems to be a better period for this practice. At that time growth is much better, resulting in a better quality and possibly the same degree of earliness. It seems worthwhile to find out which period is most suitable for 24-hours lighting to promote earlier flower initiation.

At the end of the summer the growth period between pinching and flower initiation started to increase on approximately 1 October (Fig. 1). But the vegetative-generative switch at cellular level must be regarded to have occurred some weeks earlier and thus at a daylength of more than 12 hours. This is approximately the same daylength as in the beginning of the season. Thus, flower initiation in young shoots can be postponed during summer by restricting the daylength to approximately 12 hours, as was already suggested by Münch (1973). This procedure may offer a second possibility to lower the peak in commercial carnation production. 


\section{KLAPWIJK}

Temperature differences occurring in the present experiments have probably not confused the results with respect to flower initiation and flowering, since Bunt (1974) and Bunt \& Powell (1983) concluded that temperature was not an important factor influencing flower initiation.

\section{Maximum number of leaf pairs}

The maximum number of leaf pairs below the flower is also an important criterion with respect to flower initiation. The date the maximum leaf number was reached was derived from the curve of leaf initiation, which was determined for all batches. In Fig. 3 the maximum leaf number is related to the date the last leaf pair was recorded. The same pattern as in Fig. 2 was found. This implies that in winter the plants continue to initiate new leaf pairs and that flowering is postponed. At a certain critical daylength all shoots with 19 or more leaf pairs switch to the generative stage. As a result the number of leaf pairs decreased promptly from a maximum of 24 to the minimum value of about 19 per shoot (Fig. 3). The lowest total number of leaf pairs was more than 18, including all leaf pairs from the lowest part of the stem to those lying against the calyx. From Figs. 1,2 and 3 the conclusion can be drawn that flower initiation was affected by daylength, and the vegetative growth properties (Klapwijk, 1987) reacted on the amount of incoming radiant energy.

The value for required number of leaf pairs mentioned by Bunt (1973) and Abou Dahab (1967) was about 4-6 lower than we found in the present experiments. Probably only macroscopically visible leaves had been taken into account by these authors. Nevertheless, year-round patterns found by Bunt (1973) and Abou Dahab (1967) agreed with the results presented here.

\section{Shoot extension and flower initiation}

Of each of the 32 batches of plants shoot length was recorded at regular time intervals. In every planting the rate of stem extension showed a three-fold increase from the moment flower initiation was observed under the microscope. The date on

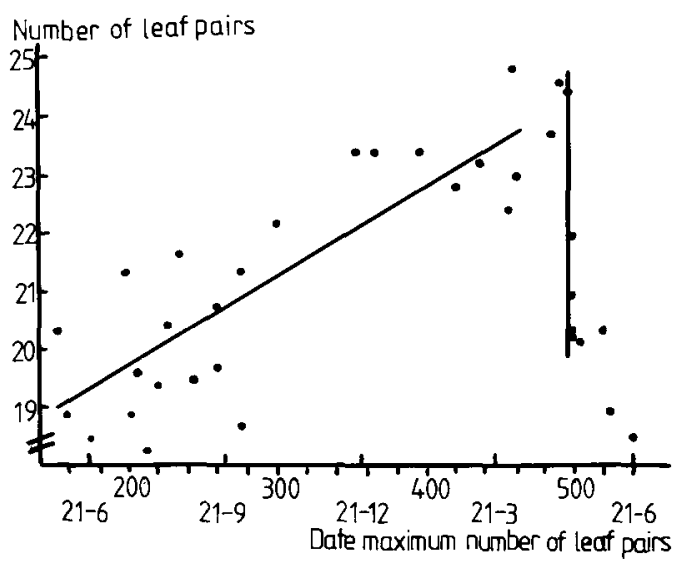

Fig. 3. Maximum number of leaf pairs in carnation shoots, in relation to the date the maximum number of leaf pairs was determined. Regression equation: $152 \leqslant$ $x \leqslant 455 ; y=0.0153 x+16.6 ; r=0.834$. 


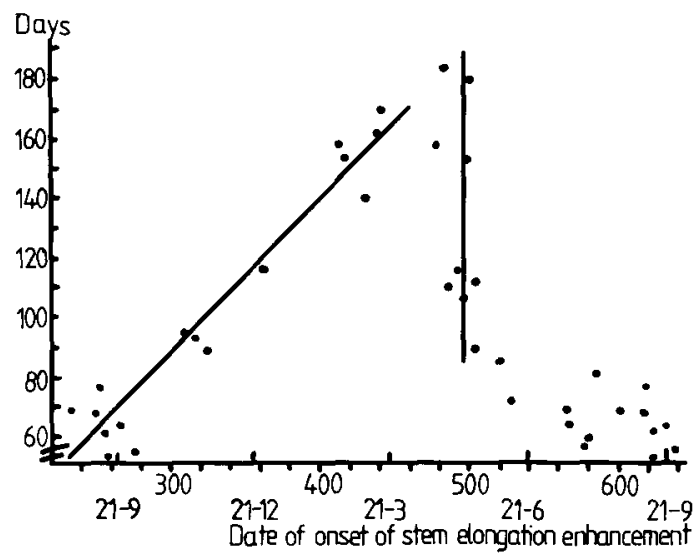

Fig. 4. Growth period (days) of vegetative carnation shoots between pinching and enhancement of stem elongation rate (see text), in relation to the moment of onset of this enhancement. Regression equation: $234 \leqslant x \leqslant 431 ; y=0.051 x$ $-64.7 ; r=0.971$.

which the prompt increase in stem length occurred was calculated for all plantings. The number of days required from pinching to the start of increase in extension rate, related to the date the increase took place, is presented in Fig. 4. The growth period was only about one week shorter than recorded via flower initiation (Fig. 2). This implies that the extension reaction occurs closer to the moment of vegetativegenerative switch at cellular level. These relationships provide the possibility to determine flower initiation non-destructively by frequent measurements of stem elongation.

\section{Growth period until flowering}

Much work has been done to study seasonal effects on flowering of standard carnation. Seven year-round series have been reported (Abou Dahab, 1967; Anon., 1982; Bing, 1960; Bunt, 1973; Holley, 1959; Nelson \& Kiplinger, 1957; Münch, 1973). These literature data, mostly referring to the entire period between pinching and flowering, are presented in Fig. 5 with the present results as a reference. From these sets of data we calculated the average flowering date at which the abrupt decrease in growth period occurred. The average date was 21 June. The band width of the abrupt decrease around 21 June is approximately 40 days. The experimental results of Holley (1959), which are a compilation of 8 years of experimentation, are completely different from Fig. 5, since he presented an almost constant period between pinching and flowering of 150 days, with a decrease to 100 days in AugustSeptember. An explanation cannot be given here.

Obviously, effects of daylength on the development of carnation is similar in all experiments cited, except Holley's. There is a rather important geographical difference in the length of the growth periods (Fig. 5). Carnations in Western Germany (Münch, 1973) and Korea (Anon., 1982) required 7 weeks more until flowering than those in the experiments of Bunt (1973) in the United Kingdom and those of Nelson \& Kiplinger (1957) in Ohio, USA. The explanation may be the different growing conditions and different parameters used, such as planting date instead of 


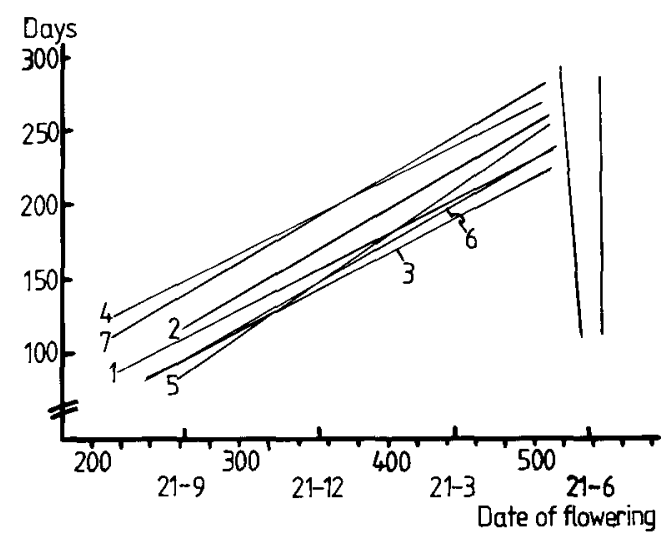

Fig. 5. Growth period (days) of carnation shoots from pinching/planting till flowering, calculated from: (1) this work; (2) Abou Dahab, 1967, Netherlands; (3) Bunt, 1973, United Kingdom; (4) Münch, 1973, Federal Republic of Germany; (5) Bing, 1960, New York, USA; (6) Nelson \& Kiplinger, 1957, Ohio, USA; (7) Anonymous, 1982, South Korea.

pinching date. The spray carnation used in the present work did not react differently from the standard cultivars used in all experiments cited above.

\section{Spray carnation vs. standard carnation}

In two cases 'Sim' carnation (cv. White Sim) was planted at the same time as spray carnation. One batch was pinched on 4 June, which resulted in the almost shortest observed period until flower initiation. The other batch was pinched on 12 September being the planting with the almost longest observed period between pinching and flower initiation. The maximum number of leaf pairs per plant was 18.4 and 17.4 respectively for West Pink and White Sim when pinched on 4 June, and 21.2 and 21.9 when pinched on 12 September. The respective number of days needed to reach flower initiation was 56 and 54 days when pinched on 4 June, and 173 and 170 days when pinched on 12 September.

These data support the conclusion that standard carnation cultivars respond to natural daylength in the same way as spray carnation.

\section{Conclusions and recommendations}

- The critical daylength for flower initiation in spray carnation is approximately 13 hours. This offers the possibility for earlier flower initiation by extending daylength during the months preceding 13 hours daylength (February-March).

- In commercial production, daylength extension is practiced in January. The results obtained in the present study suggest that research is required to determine whether this might better be done in March. Research should also be carried out to verify whether it is possible to postpone summer flowering by restricting daylength in July-August to less than 13 hours.

- Frequent measurements of shoot length offer a non-destructive method to determine flower initiation.

- With respect to flower initiation it is very probable that spray carnation and standard carnation react similarly to daylength. 


\section{References}

Abou Dahab, A. M., 1967. Effects of light and temperature on growth and flowering of carnation (Dianthus caryophyllus L.). Communications Agricultural University, Wageningen 67-13;68 pp.

Anonymous, 1982. Effect of cut-flower yield and quality by pinching methods and planting time of carnation. Annual Research Report for 1981, Ministry of Agriculture and Fisheries, Suweon, Republic of Korea, p. 114-115.

Bing, A., 1960. Timing your carnation crop. New York State Flower Growers Bulletin 172: 1-4.

Bunt, A. C., 1973. Effect of season on the carnation (Dianthus caryophyllus L.). II. Flower production. Journal of Horticultural Science 48: 315-325.

Bunt, A. C., 1974. Response of carnation to light and heat. Commercial Grower 4081: 459-464.

Bunt, A.C. \& M. C. Powell, 1983. Quantitative response of carnation to solar radiation, long days and supplementary light source. Acta Horticulturae 141: 139-150.

Cheng, L. H. \& R. W. Langhans, 1971. Floral initiation, development, and associated phenomena of Dianthus carvophyllus L. Part I - Effect of photoperiod. Journal of the American Society for Horticultural Science 96(4): 504-509.

Hanzel, R. J., K. S. Nelson \& D. C. Kiplinger, 1955. Floral initiation and development in the carnation, Var. Northland. Proceedings of the American Society for Horticultural Science 65: 455-462.

Holley, W. D., 1959. Crop control on carnations. Bulletin 110, Colorado Flower Growers Association; 4 pp.

Klapwijk, D., 1987. Effect of seasonal radiation and daylength shifts on growth and development of spray carnation. 1. Vegetative growth. Netherlands Journal of Agricultural Science 35: 55-62.

Nelson, K. S. \& D. C. Kiplinger, 1957. Carnation crop control. Research Bulletin 786, Ohio Agricultural Experiment Station, Wooster; $51 \mathrm{pp}$.

Münch, J., 1973. Die Steuerung des Blühtermins. Der Erwerbsgärtner 26: 1273-1278. 